\title{
How patients perceive the role of hospital chaplains: a preliminary exploration
}

\author{
Jennifer M Ellis, Chris McManus, Barrie A Newton
}

\begin{abstract}
Objective-An exploratory study of the attitudes of hospital patients to the service provided by hospital chaplains.

Design-Questionnaire study of hospital inpatients in December 1992.

Setting-One large teaching hospital in London.

Patients-180 hospital inpatients in 14 different general wards, $168(93 \%)$ of whom agreed to take part.

Main measures-Attitudes to chaplains and their role contained in 12 questions developed during a pilot study on hospital inpatients (16) and staff (14) and their relation to patients' age, sex, length of hospital stay, and religious beliefs, according to Kendall rank order correlations.

Results-Of 168(93\%) respondents, $72(43 \%)$ were women; mean age of patients was $63 \cdot 1(\mathrm{SD} 16 \cdot 8)$ years. Forty five $(27 \%)$ were inpatients of three days or less and $22(13 \%)$ for one month or more. $136(81 \%)$ were Christian; $17(10 \%)$ atheist, agnostic, or had no religion; and $15(9 \%)$ were of other religions. In general, patients showed positive attitudes towards the role of hospital chaplains and to the services they provided. The correlation analysis showed that there was a significant tendency for older patients, those who had been inpatients for longer, and those with religious beliefs to be more sympathetic to the role of hospital chaplains.
\end{abstract}

Conclusions-Hospital chaplains provide a service which is appreciated by patients. This study provides a simple instrument for assessing patients' attitudes to chaplains.

(Quality in Health Care 1995;4:174-177)

Keywords: Hospital chaplains, patients' perceptions, questionnaire survey

St Mary's Hospital Medical School, Imperial College of Science, Technology and Medicine,

London W2 1PG

Chris McManus, professor of psychology

St Mary's Hospital,

Praed Street

London W2 1NY

Jennifer M Ellis, house

officer

Barrie A Newton,

hospital chaplain

Correspondence to:

Professor McManus

Accepted for publication 16 June 1995 are aware is that of Koenig et $a l^{23}$ in the fourmal of Pastoral Care, which is not indexed in using Medline disclosed almost no empiric research of the services provided by hospital chaplains, their attitudes, or the perception of
Medline. We therefore describe an exploratory study of patients' perception of chaplains in one large teaching hospital and thereby hope to stimulate further research into other aspects of the care that chaplains provide. The overall scarcity of research of the role of chaplains and of pastoral care in hospital settings is surprising in view of the long and wide ranging interest of the behavioural sciences in the psychological ${ }^{4-6}$ and sociall $^{7-9}$ bases of religion in general. Importantly, in a recent large scale survey of hospital patients $6 \%$ "thought that their religious practices were not respected." 10

Since its inception an aim of the National Health Service (NHS) has been "to provide for the spiritual needs of both patients and staff," 11 and today the first of the national standards listed in the patient's charter requires "respect for privacy, dignity and religious and cultural beliefs for all patients who seek health care" (our emphasis). In the NHS there are about 5000 hospital chaplains, 250 of whom are full time; they are employed under the terms of Department of Health and Social Security (DHSS) Personnel Memorandum PM(84) 10, ${ }^{11}$ and professional standards are set through the College of Health Care Chaplains. ${ }^{12} \mathrm{Re}-$ organisation of the NHS has provoked fears of cuts in a service that remains "stubbornly unquantifiable ... in terms of tears dried, words of comfort given, and peaceful deaths achieved," 13 which might provide a "soft target" for health authorities wishing to trim budgets. ${ }^{14}$ Here we attempt to quantify some aspects of the work of a hospital chaplaincy, as perceived by patients in one hospital.

\section{Patients and methods}

Inpatients at St Mary's Hospital, London, in December 1992 completed a one page questionnaire concerning "chaplains," defined as "a priest, minister of the church, or a nun based in the hospital." Despite its name the hospital is not a religious foundation and has no specifically Roman Catholic links; however, the principal catchment area of the hospital in north west London does contain a fairly high number of Roman Catholics, particularly among the large population of people of Irish and Southern European origin. The hospital NHS trust pays for one full time (Anglican) chaplain and four part time chaplains (two Anglican, one Roman Catholic, and one Free Church); in addition, at the time of the survey the visitation committee of the Office of the Chief Rabbi also employed a part time visiting rabbi.

When a patient's faith is known he or she will be visited by a person of the appropriate faith. Although no chaplains or equivalents are 
specifically employed for other faiths, all hospital wards have appropriate contacts, which can also be made through the hospital chaplaincy. The employed chaplains make a point of visiting all inpatients, irrespective of faith, to arrange specific help when necessary. Experience has shown that hospital visiting is principally part of the Judaeo-Christian tradition and that other faiths put less emphasis on specific ministration to the sick and that specific religious ceremonies relating to illness or death are the responsibility of family members.

The attitudinal items on the questionnaire systematically covered the major areas of interest recorded from 16 patients and 14 hospital staff interviewed in a pilot study. Those interviews were transcribed, and about one hundred separate statements identified which concerned aspects of a chaplain's work. The statements were written on index cards and then sorted by JME and CM into groups with similar meaning, after which a canonical item was formed for each group which expressed the major concerns in a simple and comprehensible form. The draft version of the questionnaire (see appendix), which also included questions on age, sex, duration of stay in hospital, and religious group, was piloted on patients of one hospital ward for understandability and acceptability and was found to be adequate. Although one of the hospital chaplains (BAN) was involved in the origination and planning of the study and the chaplaincy generally was aware of the study, they were not involved in the choice of specific questions nor in collecting data, which was carried out entirely by JME.

In the study proper, patients in 14 different wards were asked individually by JME to complete the questionnaire, and in each case the questionnaire was handed over personally. If patients could not complete the questionnaire themselves for any reason JME read the items aloud to them and they indicated their responses. If patients were asleep, busy, or elsewhere then JME returned at a later time on three separate occasions to maximise the rate of inclusion. Patients were studied in all "general" wards, excluding the intensive care unit, coronary care unit, accident and emergency department, paediatric and obstetric wards, and the ward specialising in care of patients with AIDS.

Statistical analysis was principally descriptive, describing the proportions of patients responding to each of the items. In addition, Kendall rank order correlations were used to assess whether particular responses related to the patients' sex, age, length of stay in hospital, or holding of religious beliefs. A factor analysis was also carried out in a preliminary attempt to assess the dimensionality of the attitudinal items.

\section{Results}

Overall, 180 patients were studied, and the response rate was $93 \%$ (12 patients refused to participate or were persistently asleep or absent from the ward). Of the 168 respondents, $72(43 \%)$ were female; the mean age was $63 \cdot 1$ years (standard deviation $16 \cdot 8$, range 19-87 years). A total of $45(27 \%)$ had been in hospital for three days or less and $22(13 \%)$ for one month or longer; $136(81 \%)$ described their religion as Christian (of whom $57(42 \%$ ) were Roman Catholics); $17(10 \%)$ as none, atheist, or agnostic; and $15(9 \%)$ as other.

The table shows the patients' responses to each question. Most patients reported positive attitudes towards hospital chaplains: they felt chaplains were an important part of the team of carers, who were particularly trained to listen, whose job principally concerned patients' religious needs, and who were not merely counsellors. Clothing to indicate chaplains' religious vocation was appreciated, as was the existence of a hospital chapel. A chaplain's role

Responses of 168 patients to questionnaire on role of hospital chaplains and the Kendall rank-order correlations of responses with patients' sex, age, duration of hospital stay, and religious beliefs

\begin{tabular}{|c|c|c|c|c|c|c|c|c|}
\hline \multirow[t]{2}{*}{ Topic } & \multirow{2}{*}{$\begin{array}{c}\% \\
\text { Strongly } \\
\text { agree }\end{array}$} & \multirow{2}{*}{$\begin{array}{l}\% \\
\text { Mildly } \\
\text { agree }\end{array}$} & \multirow{2}{*}{$\begin{array}{c}\% \\
\text { Mildly } \\
\text { disagree }\end{array}$} & \multirow{2}{*}{$\begin{array}{c}\% \\
\text { Strongly } \\
\text { disagree }\end{array}$} & \multicolumn{4}{|c|}{ Correlations with: } \\
\hline & & & & & $\operatorname{Sex} x^{I}$ & $\mathrm{Age}^{2}$ & $\begin{array}{l}\text { Length } \\
\text { of stay }\end{array}$ & $\begin{array}{c}\text { Religious } \\
\text { beliefs }^{4}\end{array}$ \\
\hline \multirow{3}{*}{$\begin{array}{l}1 \text { Important part of the healthcare team } \\
2 \text { Trained to listen, help, and provide comfort and reassurance in confidence } \\
3 \text { Principally help patients with their religious needs } \\
4 \text { Should attempt to see all patients at some point in their stay } \\
5 \text { Reassuring to see chaplains wearing something indicating an ordained minister } \\
6 \text { Should devote most time to seriously ill patients } \\
7 \text { Important for hospitals to have a chapel, where services can be held, } \\
\text { and where patients or relatives can go for peace and quiet } \\
8 \text { Counsellors could do a chaplain's job just as well } \\
9 \text { Even if not seriously ill and had not required it, a chaplain's visit would be welcome } \\
10 \text { Chaplain's visit if not requested would cause offence } \\
11 \text { Chaplain reading the bible or praying with a neighbouring patient would cause offence } \\
12 \text { Knowledge of how to contact chaplain }\end{array}$} & $\begin{array}{l}59 \\
66 \\
48 \\
48 \\
61 \\
39\end{array}$ & $\begin{array}{l}31 \\
27 \\
31 \\
37 \\
26 \\
35\end{array}$ & $\begin{array}{r}7 \\
3 \\
16 \\
10 \\
8 \\
19\end{array}$ & $\begin{array}{l}3 \\
3 \\
5 \\
5 \\
4 \\
8\end{array}$ & $\begin{array}{c}-0.12^{\mathrm{a}} \\
-0.05 \\
-0.19^{\mathrm{c}} \\
0.00 \\
-0.03 \\
-0.07\end{array}$ & $\begin{array}{l}0.20^{\mathrm{c}} \\
0 \cdot 11^{\mathrm{a}} \\
0.07 \\
0.23^{\mathrm{d}} \\
0 \cdot 13^{\mathrm{b}} \\
-0.07\end{array}$ & $\begin{array}{c}0.15^{\mathrm{b}} \\
0 \cdot 11^{\mathrm{a}} \\
0.01 \\
0.11^{\mathrm{a}} \\
-0.06 \\
0 \cdot 10\end{array}$ & $\begin{array}{l}0 \cdot 26^{\mathrm{d}} \\
0 \cdot 22^{\mathrm{c}} \\
0.06 \\
0 \cdot 24^{\mathrm{c}} \\
0.23^{\mathrm{c}} \\
0.03\end{array}$ \\
\hline & $\begin{array}{r}73 \\
15 \\
40 \\
7 \\
11 \\
31\end{array}$ & $\begin{array}{r}20 \\
26 \\
41 \\
16 \\
8 \\
22\end{array}$ & $\begin{array}{r}5 \\
24 \\
13 \\
16 \\
11 \\
17\end{array}$ & $\begin{array}{r}2 \\
36 \\
6 \\
62 \\
70 \\
30\end{array}$ & $\begin{array}{c}0.07 \\
-0.18^{\mathrm{b}} \\
0.03 \\
0.09 \\
-0.15^{\mathrm{b}} \\
-0.02\end{array}$ & $\begin{array}{r}0.07 \\
0.04 \\
0.16^{\mathrm{b}} \\
-0.03 \\
0.04 \\
-0.06\end{array}$ & $\begin{array}{l}0.12^{\mathrm{a}} \\
0.02 \\
0 \cdot 11^{\mathrm{a}} \\
0.01 \\
0.07 \\
0 \cdot 10^{\mathrm{a}}\end{array}$ & $\begin{array}{c}0.29^{\mathrm{d}} \\
-0.03 \\
0.36^{\mathrm{d}} \\
-0.01 \\
0.00 \\
0.06\end{array}$ \\
\hline & \multicolumn{2}{|c|}{$\%$ Yes } & \multicolumn{2}{|c|}{$\%$ No } & & & & \\
\hline $\begin{array}{l}13 \text { Patient asked about their religion } \\
14 \text { Patient asked to see hospital chaplain } \\
15 \text { Patient talked to hospital chaplain }\end{array}$ & \multicolumn{2}{|c|}{$\begin{array}{l}64 \\
14 \\
40\end{array}$} & \multicolumn{2}{|c|}{$\begin{array}{l}36 \\
86 \\
60\end{array}$} & $\begin{array}{r}-0.03 \\
-0.01 \\
0.02\end{array}$ & $\begin{array}{r}-0.01 \\
0.08 \\
0.07\end{array}$ & $\begin{array}{r}-0 \cdot 12^{\mathrm{a}} \\
0 \cdot 21^{\mathrm{c}} \\
0 \cdot 41^{\mathrm{d}}\end{array}$ & $\begin{array}{r}0.01 \\
-0 \cdot 03 \\
0.08\end{array}$ \\
\hline
\end{tabular}

A positive (negative) correlation indicates that women (men) were more likely to agree with the statement or answer yes.

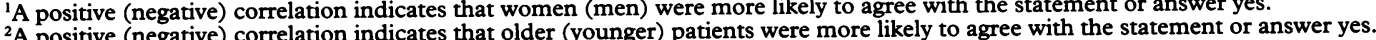

${ }_{3}^{2}$ positive (negative) correlation indicates that older (y inger) pat longer (for less time) were more likely to agree with the statement or answer yes.

A positive (negative) correlation indicates that patients with (without) religious beliefs were more likely to agree with the statement or answer yes.

${ }^{2} \mathrm{~A}$ positive

${ }^{2} \mathrm{p}<0.01$.

${ }^{\mathrm{b}} \mathrm{p}<0.05$.

$\mathrm{p}<0.01$.
$\mathrm{p}<0.01$. 
was seen as principally with seriously ill inpatients, although it was desirable if all patients could be visited. Patients would not be offended by a chaplain's visit, even when not seriously ill, and would not be offended by chaplains praying or reading the bible with a neighbouring patient. Half the patients knew how to contact a chaplain, and $14 \%$ had asked to see a chaplain during their current stay. In all, $40 \%$ of patients had talked to a chaplain during their current stay, the proportion increasing with increasing length of stay $(12 \%, 5 / 42$ at $1-3$ days; $48 \%, 45 / 93$ at $4-30$ days; $75 \%, 15 / 20$ at one month or more). In all, $64 \%$ of patients recalled being asked about their religion on admission, although since the proportion declined with length of stay, some patients may have forgotten $(76 \%, 32 / 42,1-3$ days; $59 \%, 50 / 85,4-30$ days; $65 \%, 11 / 17$, one month or more).

The table also shows the correlation of responses with four demographic measures: sex, age, hospital stay, and religious beliefs (atheist, agnostic, and none compared with holding of beliefs). Women saw the chaplain's role as less specifically religious; older patients regarded the chaplains as more part of the caring team, who should visit all patients in hospital; and patients in hospital for longer had asked more to see a chaplain and had talked to them. Predictably, patients with religious beliefs differed on several of the questions. Interestingly for six questions religious beliefs showed no relation to attitudes to chaplains.

The psychometric structure of a questionnaire is best assessed by means of a factor analysis, which looks at the number of statistically independent dimensions or factors that can be found in the data. ${ }^{15}$ Factor analysis of the responses to the questions was carried out by a principal components analysis (which identifies the factors accounting for the maximum amount of variability in the data), followed by varimax rotation (which "rotates" the dimensions to maximise the ease with which they can be interpreted, or made sense of). ${ }^{16}$ Scree slope analysis, ${ }^{17}$ which is used to determine the number of independent factors present within the data after the principal components analysis, suggested the presence of two separate factors. Inspection of the factor loadings after the varimax rotation suggested that Factor II comprised items 8, 10, and 11, all of which loaded positively with loadings greater than $0 \cdot 45$. This factor is probably best interpreted as a specific hostility to the role of a chaplain, with two of the terms including the word "offended," and the third suggesting that chaplains could be replaced by counsellors. The remaining nine items which formed Factor I had positive loadings of greater than 0.45 in all cases but one, the exception being item 6 , which had a loading of $0 \cdot 35$. The factor is best interpreted in terms of general overall positive attitudes to the role of the chaplain in hospital. Taken together the factor analysis suggests that the 12 items could, if necessary, be reduced to a smaller number of items based around the items loading specifically on each of the two factors.

\section{Discussion}

Although this is only a preliminary and exploratory study, the data obtained confirm that most inpatients had positive feelings about many aspects of a chaplain's role. Unsurprisingly, patients with religious beliefs were more likely to hold positive attitudes. Nevertheless, a minority of patients, who were more likely to be male and identifiable from the factor analysis, showed negative attitudes and are offended by their presence. Clearly, hospital chaplains must take such attitudes into account in carrying out their daily work.

Hospitals provide not only medical care but also pastoral care within the broadest meanings of that term. Hospital chaplains provide an important and sometimes neglected aspect of such care. The simple 12 item questionnaire described in this study provides a straightforward way of assessing patients' views of the role of hospital chaplains. We believe that the questionnaire will make a convenient research instrument for future, more extensive, studies.

Overall, hospital chaplains are appreciated and accepted by most patients, with few differences related to age, sex, length of stay, or religious beliefs. Chaplains have been an important part of the service provided by the NHS since its inception, ${ }^{11}$ and a respect for patients' religious needs is included within the patient's charter. ${ }^{12}$ Most patients, by no means all of whom are specifically religious themselves, seem to wish that to continue as an integral part of hospital care. The quality of care provided by hospitals cannot be assessed only in terms of strictly medical outcomes: as complex social institutions they provide care in many ways, one of which is through consideration of the spiritual as well as the temporal needs of their patients. Our results indicate that hospital chaplains seem to make an important contribution to care in the broadest sense.

We thank Belinda Winder and Kerry Sproston for their help with data processing.

1 Autton N. Pastoral care in hospitals. London: SPCK, 1969. Koenig HG, Bearson LB, Hover M, Travis JL, III. Religious perspectives of doctors, nurses, patients and families. Fournal of Pastoral Care 1994;45:254-67.

Hover M, Travis JL, III, Koenig HG, Bearson LB. Pastoral research in a hospital setting: a case study. Fournal of Pastoral Care 1992;46:283-90.

James W. The varieties of religious experience: a study in human nature. New York: Longmans and Green, 1902.

5 Wulff DM. Psychology of religion. Classic and contemporary views. Chichester: J Wiley, 1991.

6 Gorsuch RL. Psychology of religion. Annu Rev Psychol 1988;39:201-21.

Robertson $\mathbf{R}$, ed. Sociology of religion: selected readings. Harmondsworth: Penguin, 1969

8 Argyle M, Beit-Hallahmi B. The social psychology of religion. London: Routledge and Kegan Paul, 1975.

9 Argyle M. The social psychology of everyday life. London: Routledge, 1992 .

10 Bruster S, Jarman B, Bosanquet N, Weston D, Erens $R$ Delbanco TL. National survey of hospital patients. $B M \mathcal{J}$
Delans

11 Hospital Chaplaincies Council. $A$ handbook on hospital chaplaincy. London: General Synod of the Church of England, 1987.

12 Speck P. Nursing the soul. Nursing Times 1992;88:22.

13 Editorial. Comment. Nursing Times 1990;86:3

14 Sims J. A willing ear and a gentle, caring touch. Independen 1991 Feb 26:17.

15 Kline B. An easy guide to factor analysis. London: Routledge, 1994.

16 Child D. The essentials of factor analysis. London: Cassell Educational, 1990.

17 Zwick WR, Velicer WF. Comparison of five rules for determining the number of components to retain. Psychol Bull 1986;99:432-42. 


\section{Appendix}

\section{Hospital chaplains: a survey}

We are interested in what all of our patients know about the hospital chaplain and what they think their job should be. We would be grateful if you could help us with our study by answering a few questions.

Simply indicate your opinion by ringing one of the replies to each question. There are no right or wrong answers, and of course all replies will be kept strictly confidential and used only for our research.

Please note: the word "chaplain" means a priest, a minister of the church or a nun who is based in the hospital. Thank you for your help

1 Chaplains are an important part of the team of people looking after a patient Strongly agree / mildly agree / mildly disagree / strongly disagree

2 A chaplain is trained to listen, to help with difficult problems, and to provide comfort and reassurance in complete confidence, for all patients

Strongly agree / mildly agree / mildly disagree / strongly disagree

3 The job of a chaplain is principally to help patients with their religious needs Strongly agree / mildly agree / mildly disagree / strongly disagree

4 Hospital chaplains should try to see everyone in the hospital at some point during their stay Strongly agree / mildly agree / mildly disagree / strongly disagree

$5 \mathrm{It}$ is reassuring to see chaplains wearing something to indicate that they are an ordained minister Strongly agree / mildly agree / mildly disagree / strongly disagree

6 Chaplains should devote most of their time to patients who are seriously ill Strongly agree / mildly agree / mildly disagree / strongly disagree

7 It is important that hospitals have a chapel, where services can be held, and where patients or relatives can go for peace and quiet Strongly agree / mildly agree / mildly disagree / strongly disagree

8 Counsellors could do the job of a chaplain just as well as chaplains do Strongly agree / mildly agree / mildly disagree / strongly disagree

9 Even if I was not seriously ill and had not asked a chaplain to come and see me, I would like it if a hospital chaplain came to talk to me

Strongly agree / mildly agree / mildly disagree / strongly disagree

10 I would be offended if a chaplain came and spoke to me if I had not asked to see one Strongly agree / mildly agree / mildly disagree / strongly disagree

11 If the chaplain read the bible or prayed with the person in the next bed to me I would be offended Strongly agree / mildly agree / mildly disagree / strongly disagree

12 If I wanted to see the chaplain I would know how to contact them Strongly agree / mildly agree / mildly disagree / strongly disagree

Finally, a few questions about yourself:

1 When you came into hospital were you asked what your religion is?

2 Have you asked to see a hospital chaplain on this visit to hospital?

3 Have you talked to a hospital chaplain during this hospital visit?

4 How old are you? years

5. Are you male or female?

6 How long have you been in hospital?

7 What is your religion?

Christian / Fewish / Muslim / Hindu / Sikh / Buddhist / None / Agnostic / Atheist / Other

8 If you are a Christian, what is your denomination? 